\title{
Research on the Application of Computer Graphic Advertisement Design Based on a Genetic Algorithm and TRIZ Theory
}

\author{
Yang Song*
}

School of Academy of fine arts, Baotou Teachers College; Baotou Inner Mongolia, 014030 (China)

Received 2 November 2020 | Accepted 17 April 2021 | Published 5 August 2021

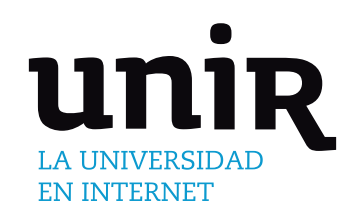

In view of the shortcomings of the traditional thinking of computer graphic advertising design, this paper introduces TRIZ innovative thinking to design computer advertising. First of all, combined with specific cases of computer creative print advertising, this paper analyzes the creative methods of stimulating divergent thinking, aggregation thinking and transformation thinking from the innovation principle of TRIZ theory as the origin, and applies them to the creative mechanism and application program of print advertising creativity. The whole process is led by rational principles of perceptual thinking, driven by specific principles of abstract imagination, to explore the thinking source of creative design essence of print advertising. The theory and its application mechanism become a new thinking method and application attempt in the creative field of print advertisement. Then, based on the TRIZ innovation theory, the business model of advertising content arrangement is constructed, and the mathematical model is constructed according to the planning business media resource planning on the business model to realize the multi-objective optimization of efficient use of orders and precise delivery of time. Finally, a multi-objective optimization mathematical model of parallel genetic algorithm is designed to solve the advertisement content arrangement. The innovative thinking of TRIZ and the application of genetic algorithm in content arrangement of computer graphic advertisement design are verified by experiments.

\author{
Content Arrangement, \\ Genetic Algorithm, \\ Innovative Thinking, \\ Print Advertising, TRIZ \\ Theory.
}

DOI: $10.9781 /$ ijimai.2021.08.007

\section{The Application of TRIZ Theory in Computer Graphic Advertisement Design}

\section{A. An Overview of TRIZ Theory}

\section{The Concept of TRIZ Theory}

TRIZ (theory of the solution of innovative problems from Russian) is translated into "theory of solving invention problems." TRIZ provides comprehensive theory and method tools for people to solve problems creatively. The three basic theoretical bases are as follows [1]:

1. In the practice of solving problems, various contradictions and corresponding solutions are always repeated;

2. There are not many innovative principles and methods to solve problems thoroughly rather than compromise, which can be learned and mastered by ordinary scientific and technological personnel;

3. The most effective principles and methods to solve this field's problems often come from scientific knowledge in other areas [2]. After more than half a century of development, TRIZ theory has been widely used in many fields worldwide, it has not been applied to the creative design of print advertising.

${ }^{*}$ Corresponding author.

E-mail address: songyang1008@yeah.net

\section{The Relevance Between TRIZ's Core Idea and Creative Thinking of Print Advertisement}

In recent years, the research on TRIZ theory in the field of innovation is on the rise. At present, TRIZ has penetrated from the initial engineering technology field to social science, management science, and other fields. Interdisciplinary knowledge acquisition is significant [3]. When people encounter difficult problems, they can seek knowledge of their discipline and expand outside the discipline to find solutions in other professional fields. The scientific principles of innovative design often belong to other fields. This core idea is in line with this study's theme, applying TRIZ theory in the creative thinking of print advertising. Computer graphics is the computer science branch that uses a computer to create images. Today's dominant technology is computer graphics in digital imaging, animation, video games, cellular and computer displays, and various specialist applications. Computer graphics can be a method for growing student knowledge of science topics like mathematics. Through real-time, interactive, and visual input, students can easily see the impact of mathematics on creating successful designs. Graphic designers prepare, evaluate, and create visual solutions for communication issues using color, form, illustration, photography, animation, various printing and layout technology to distinguish print and electronic media messages. Graphic designers produce and manufacture multiple magazines, newspapers, journals, business reports, and other publications as a whole and work in various ways in advertising. Graphic designers 
have some responsibility in advertising, including the manufacture of promotional panels, product and service packaging and marketing brochures, logos design for goods and organizations, and the creation of signs and signage systems for businesses and governments. Graphic designers often create computer and internet materials, including webpage, digital, and virtual media projects.

\section{B. Combination of TRIZ Innovation Principle and Traditional Creative Thinking Method}

\section{The Innovative Principle of TRIZ Theory}

The principle of TRIZ innovation is to use scientific discovery principles and methods to analyze and solve problems rationally and thoroughly. It contains the common principles followed by human innovation. It is the earliest, most basic, most core, and the highest practical utilization rate of TRIZ theory. It is useful and easy to learn and master, as shown in Table I.

TABLE I. Key InNovation Principles of TRIZ Theory

\begin{tabular}{|c|c|c|}
\hline $\begin{array}{c}\text { Serial } \\
\text { Number }\end{array}$ & $\begin{array}{c}\text { Innovation } \\
\text { Principle }\end{array}$ & Specific Description \\
\hline 1 & $\begin{array}{l}\text { Segmentation } \\
\text { Principle }\end{array}$ & $\begin{array}{l}\text { (1) Divide the whole into separate parts } \\
\text { (2) Divide the total into parts that are easy to } \\
\text { assemble and easy to disassemble } \\
\text { (3) Improve the whole, separable ability, realize } \\
\text { the entire transformation }\end{array}$ \\
\hline$\ldots$ & $\cdots$ & $\cdots$ \\
\hline 5 & $\begin{array}{l}\text { Combination } \\
\text { Principle }\end{array}$ & $\begin{array}{l}\text { (1) Spatial dimension, the combination of the } \\
\text { same or similar objects } \\
\text { (2) Time dimension, which merges the same or } \\
\text { related operations }\end{array}$ \\
\hline 6 & $\begin{array}{l}\text { Versatility } \\
\text { Principle }\end{array}$ & $\begin{array}{l}\text { (1) An object has many different functions } \\
\text { (2) Trim objects that do not have necessary } \\
\text { functions }\end{array}$ \\
\hline 13 & $\begin{array}{l}\text { Reverse } \\
\text { Action } \\
\text { Principle }\end{array}$ & $\begin{array}{l}\text { (1) To turn an object upside down or inside out } \\
\text { (2) To change the motion of an object or } \\
\text { environment to rest }\end{array}$ \\
\hline$\cdots$ & $\cdots$ & $\cdots$ \\
\hline 14 & $\begin{array}{l}\text { Composite } \\
\text { Materials } \\
\text { Principle }\end{array}$ & $\begin{array}{l}\text { Replace the homogeneous component with a } \\
\text { composite component }\end{array}$ \\
\hline
\end{tabular}

\section{Traditional Creative Thinking Method}

1. Divergent thinking: divergent thinking is a thinking form in which the brain presents a multidimensional diffusion state. Starting from a thinking starting point, it puts forward rich ideas and seeks multiple ways to solve specific problems [4]. Authors should not stick to traditional practices and create more possibilities.

2. Aggregation thinking: aggregation thinking refers to the sublimation of logical conclusions from the existing representation and broad ideas' aggregation into a focus. It is a convergent thinking mode with scope, direction, and order [5].

3. Conversion thinking: conversion thinking is to observe objects from different aspects and angles with the perspective of connection and development, change new attitudes, avoid thinking stereotypes, and then get a comprehensive understanding of objects and complete solutions.

\section{Suitability Analysis of the Combination of TRIZ Theory and Traditional Creative Thinking Method}

1. The improvement of logicality and efficiency is the focus of existing innovative thinking methods in graphic design, whose procedures, steps, and measures are mostly based on overcoming creative psychological barriers to stimulate creative thinking [6]. Its methods are highly abstract and generalized and tend to be formalized [7]. TRIZ reveals the internal law and principle of creation. Compared with the traditional creative thinking method, it uses scientific methods to attribute special problems to TRIZ's general problems and solve the problems. TRIZ is more rapid, accurate, and efficient in the technique and process of solving problems than the traditional creative thinking method.

2. To stimulate creative thinking from the original point: TRIZ is a controllable and effective method and powerful tool to generate innovative thinking. Authors should break the inertia and one-sided restriction of thought and avoid the blindness and limitation of the traditional creative process. TRIZ theory affirms that the basic principles of creativity exist objectively. Software graphic design provides visual ideas and an innovative advertisement and marketing template. It is a pattern of the way your advertising influences your marketing. The graphics designer plays an important role in publishing information and making more enticing pictures of a product to raise the demand. It uses technology to control and combine words, images, color, and typography to create emotional feelings and transmit messages. It involves different tools, which makes the design time-efficient and straightforward. The method of images gives you many items that you can easily find where you have them to be put. Once again, when talking about coloring, then a single click fills up the region, and editing is too quick.

These principles can be sorted out and summarized into targeted design creative theories, which can shorten the creative design cycle and improve the success rate. Fig. 1 shows the case of computer graphic advertisement design under the traditional innovative thinking method.
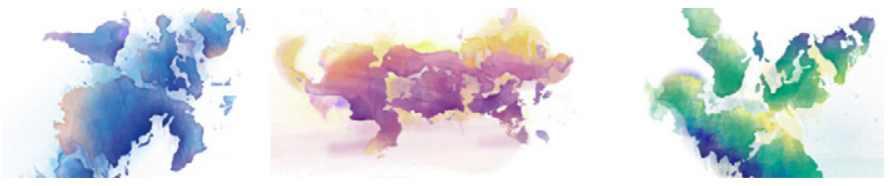

Fig. 1. Computer graphic advertisement design case under the traditional creative thinking method.

To sum up, the existing creative thinking methods have apparent deficiencies, and TRIZ can make up for them to generate more suitable innovative methods for design. However, TRIZ can solve problems creatively and achieve design innovation through scientific and rational ways. To better grasp the breakthrough point of TRIZ theory in creative thinking, it is necessary to define the innovation principle of TRIZ and traditional creative thinking. Among them, the TRIZ innovation principle focuses on the microanalysis of the expression law of creativity. In contrast, traditional creative thinking focuses on analyzing the general law of invention in the operation process from a macro perspective [8]. Computer graphics is the computer science industry that uses computers to generate images. Here Computer graphics is a central technology in digital imaging, video games, and many advanced applications. Computer graphics are the primary technology. Much specialized hardware and software have been developed, with computer graphics hardware-driven displays on most devices. The field of computer science is vast and recently established. Graphic designers are involved in professional design services such as ads, printing, related support, journals, journal books, publishers' directories, and of computer systems graphics for design companies. The emphasis is on graphical designers with website design expertise and animation experience due to increased interest in interactive media projects. As advertising companies produce prints and web marking 
and promotional materials for more products and services, especially internet advertising, graphic design demand in advertising will rise. A broad liberal education in the art and experience in marketing and management, such as the liberal advertisement and graphic design program, makes candidates more suitable for positions that work on communications strategies.

In graphic advertising design and the known traditional creative thinking methods, Authors need to explore further the thinking origin that can induce it. This paper attempts to introduce TRIZ theory into graphic advertising design, focusing on modern creative thinking methods based on TRIZ theory.

\section{Creative Thinking Method of Print Advertisement Based on TRIZ Theory}

This paper mainly introduces the combination principle, multipurpose principle, and reverse action principle of TRIZ innovation principle to stimulate the divergent thinking, aggregation thinking, and conversion thinking in traditional creative thinking and produce the method suitable for the creative thinking of print advertisement [9]. Digital graphics are the technology for design and pictures on a computer screen. Computer graphics reflect the data on a computer display visually. Computer graphics are being used to design, create, model, and catalog videos and computer programs. Nowadays, almost every machine can render such graphics, and people even anticipate controlling their device with icons and pictures instead of just typing. Design is related to areas of architecture and engineering. One of the key characteristics of most design concerns is the absence of a unique solution. The developer would then evaluate and then potentially modify a potential project to find a better solution.

Rational criteria guide the whole process, and abstract imagery is driven by specific principles to seek the thinking origin of the creative design essence of print advertisement Point. Fig. 2 shows the case design of computer print advertising under the TRIZ innovation theory thinking method.
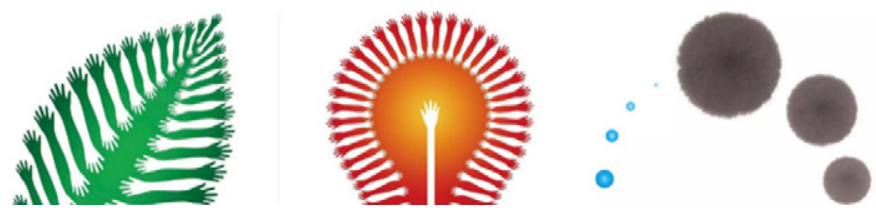

Fig. 2. Computer graphic advertisement design case under TRIZ innovative method.

\section{The Method of Stimulating Divergent Thinking With the Principle of Multi-function}

Hegel, a famous German philosopher, once said that "creative thinking needs rich imagination.” Divergent thinking is listed as the first creative thinking in design. According to the multifunctional principle of TRIZ theory, the principle that an object has many different functions is used to stimulate divergent thinking. A theme has multiple interpretations, and an item has multiple uses, which is an essential manifestation of the principle of multi-function. When the object has versatility, it can make it have more cooperation and valueadded effect at any time, place, and environment. Most of its facilities were used by computer graphics in the film and gaming industries. It has applied to movies, TV shows, cartoon animated music video, and production. In the spaces where focus and interactivity are the key players, computer graphics help provide these functions effectively. Specialized training techniques, such as simulators, may prepare applicants to be understood better within a limited period. It is easy and very useful to develop computer graphics training modules.

\section{The Method of Using the Combination Principle to Stimulate Aggregation Thinking}

The combination principle of TRIZ is to combine the same objects in space or time or objects that complete a similar operation. The deconstruction and reorganization of design elements and the introduction of new colors, new textures, and new materials into the old objects are important means of operation of the combination principle, leading to aggregation thinking through the combination principle. If the complete image is divided into a single visual element and repeatedly distributed on the screen, the same or similar methods are used to "process" one by one to make the main body repeat repeatedly and set a certain order to appear, adjust the size of specifications or color texture, etc., the final effect is often creative and has excellent visual impact. The representative's graphic instruments are used as teaching aids to educate students in the classroom. In many applications for special purposes, the computer graphics industry is commonly used. The performance of computer graphics in business applications has been seen in several ways. In its implementations the importance of computer graphics lies. The physician will view this large volume of data in new and useable ways through interactive computer graphics. Computer graphics has extended the parameters of art and entertainment.

\section{The Method of Using the Opposite Principle to Stimulate the Transformation of Thinking}

On the contrary, the principle is a different way of thinking. When using the opposite principle to stimulate the change of thinking, poster design is often concise and powerful, can lead the audience into profound thinking. Specific principles include:

1. Attribute conversion: the objects with opposite attributes are exchanged to generate new images, such as size, speed, weight, etc.;

2. The transformation of position and structure: to arrange things in the place that should not appear and change the typical structure of something;

3. Process transformation: reverse the natural law of development of things;

4. Theoretical conversion: convey the profound significance and arouse the resonance and reflection of the audience.

\section{Content Arrangement of Computer Print} Advertisement Based on a Genetic Algorithm

\section{A. A Business Model of Print Advertising Design}

The basic description and relationship of the business model [10] of print advertising design are shown in Fig. 3. Graphic designer projects in these areas can be made, including billboards, posters, logos, ads, brochures, magazines, book covers, newsletters, product packaging, website, T.V. Graphics, ads, show, video and film graphics, and graphical computer graphics. When dealing with text, graphical designers may collaborate with copywriters to fit the image of the creators. They collaborate with art managers, design directors, creation managers, account managers, printers, images, illustrators, and web developers.

Service: basic information of media channel, including number, name, description, URL or FTP address of receiving content, etc. Large advertising agencies, magazine, or design companies hire graphic designers and frequently operate in cost, lighted environments. Due to production schedules, graphics designers employed in advertisements like printers and publishers can work evenings or weekends, with shorter and more frequent deadlines. Graphic designers usually work full time in these environments. Some are self-employed. 


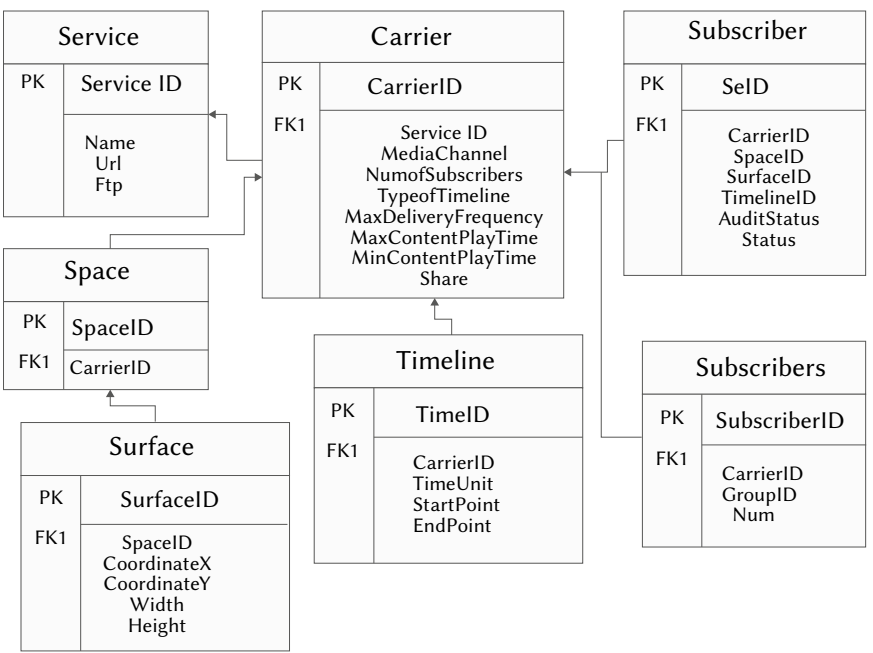

Fig. 3. Business model entity relation diagram of computer graphic advertisement design.

Carrier: the content carrying resource management that business or media channels (such as MMS Mobile News) can provide is called "carrier." All carriers can be expressed through investigation and analysis as three dimensions: space, time sequence, timeline, and subscribers. Besides, the carrier includes the basic requirements of the content arrangement, such as the maximum number of times that the same content is allowed to be put in the carrier's time axis interval, the maximum and minimum time sequence length of a single content the carrier. Web design is the expertise in creating content presentations typically delivered to the end-user through a Web browser, using hypertext or hypermedia. Different disciplines, such as animation, imagination, design of communication, business identity, graphical creation, human-computer interaction, the architecture of the content, interaction design, marketing, photography, optimization of the search engine, and typography, can be used for developing Web pages, web sites or multimedia applications.

Space: space resources are all templates and split-screen layouts created by the business administrator under a particular business. The plane is split into multiple pieces and split-screen styles. For example, Flipboard applications use rich template styles to render content.

Timeline: time-varying temporal resource description, mainly for streaming media such as focus media, digital TV, or multi-frame sequence of MMS (limited to one day). The time interval with the same business characteristics on the time axis is defined as a timeline object. Virtual Reality (VR) is a technology that allows a user to connect in a simulated computing world. For instance, simulation for pilot or combat training may be close to the real world. Virtual Reality is widely used to describe a broad range of applications often associated with its realistic, high visual 3D environment. For gaining insight into or track these processes' function, computer simulations have become a valuable part of mathematically modeling many natural systems in physical (computer physics), chemical and biologically, human systems in economies, psychology, and socio-science, as well as modern technology.

Subscribers: the audience category group of the business synchronized with the precision system, and each group of users is orthogonal and non-overlapping. In the application of CMS and its support, the audience groups can be distinguished by certain descriptive names, such as "business office building group," "family residential building group," etc., or certain user category labels such as gender, age, occupation, income range, etc. all combinations and user list binding are based on the domain values of each tag. The influence of digital technology has changed traditional activities, such as painting, drawing, and sculpture. In contrast, creative activities have been recognized for new forms such as network art, digital installer art, and virtual reality.

Subcarrier: a subcarrier is a resource block that combines specific spatial resources and material resources in a carrier. Generally, it is an independent content bearing resource block created by business administrators, which is mapped in the mobile advertising system, that is, advertising space, such as the rolling caption box at the bottom of the video terminal from 8:00 to 10:00.

Order: order is a transaction unit in CMS. It is initiated by $\mathrm{CP}$ or business administrator. It indicates the binding relationship between content and subcarrier and transaction price (input for order arrangement) and records transaction approval and operation status information.

\section{B. Mathematical Model of Content Arrangement Model}

For describing and simplifying the model solution with a mathematical language [11], this paper makes the following model assumptions and symbolic representation for the content arrangement problem.

1. The carrier is the resource object to be planned in the media layout model. In SMS / MMS, e-magazine, or advertisement, the space resource of carrier has the first dimension's priority. Therefore, multiple layout models can be constructed according to a specific location. It is simplified as a multi-group planning problem of the time axis and audience resources based on the spatial dimension.

2. Time axis resources are more important and valuable than audience resources in the content arrangement. So, the time axis is regarded as the second dimension, and the audience resources are considered to be the i-dimension resources based on the time axis.

3. Order scheduling input (Input) is the model's input data, which is defined as positive $I_{i}, i \in[1, N]$ according to the order of entering the model, where $N$ is the total number of inputs in the model; the transaction price is $P_{i}, P_{i} \in R^{+}$.

4. The media industry attaches great importance to the same timeliness and strong publicity effect of the whole audience when making the advertising layout table. For example, an advertisement is mainly broadcast on multiple TV stations at 11:59. This model supports the advertising layout's professional requirements; that is, the same order content is released to all selected audiences in the same period.

5. The model supports the accurate delivery of content by audience groups, which can be arranged and delivered to the user list associated with multiple audience groups. The number of users in the audience group can be expressed as the vector $\vec{S}=\left\{s_{j} \mid j \in[1, G]\right\}$, where $G$ is the total number of audience groups, $S_{j}$ is the number of users in the group. A positive input audience group selection Input $I_{i,}$ is described as $\vec{S}_{i}=\left\{s_{i j} \mid j \in[1, G]\right\}$ in which $s_{i j}=\left\{\begin{array}{l}1, \text { select } j \text { for Input } I_{i} \\ 0, \text { otherwise }\end{array}\right.$.

If Input $I_{i}$ does not accurately select the audience group; then it does not exist. The model supports the imprecise selection of audience number, i.e., the number of audience for content delivery can be specified during order arrangement input, which is defined as Total $_{i}, i \in[1, N]$. If the target audience $I_{i}$ is precisely selected, the number of audiences $I_{i}$ is defined as:

$\operatorname{Total}_{i}=\vec{S}_{i} \cdot \vec{S}=\sum_{j=1}^{G} s_{i j} \bullet s_{j}$

6. The time axis resources of the carrier can be continuous or discrete. In the actual content filling and advertising sales, the transaction 
unit of time sequence often has time granularity. For example, the advertising space of G3 media requires that the content playtime should be multiple of 5 seconds [12]. The time series is divided into the smallest granularity in the model, and the continuoustime periods are discretized. The planning of time axis resources is based on a discrete sequence. Therefore, to simplify the algorithm and model description, it is assumed that there is a one-time axis resource of the carrier, which is defined as $[0, T]$. Suppose the primetime interval is defined as: 11:45-12:15, with 5 seconds as the time granularity division unit. In that case, there are 360 value sets in the time axis discrete sequence, that is is $T=360$, the time interval is described as $[0,360]$.

7. The model supports the content delivery at the precise time; the content sequence length is defined as $l_{i}, l_{i} \leq T$; the expected precise timing point $d_{i}, d_{i} \in[1, T] d_{i} \in Z$. The penalty factor for the advance or delay of order scheduling in unit price unit time unit is $\alpha, \alpha \in$ $[0,1]$.

\section{Definition and Objective Function of Model Variables}

\section{Definition of Model Variables}

$X_{i j}(t)$, where $t$ is a time sequence point on the timeline resource, which means that the content arrangement starts at the $t$ time point and ends at the $t+l_{i}$ time point:

$$
X_{i j}(t)=\left\{\begin{array}{l}
1, I_{i} \text { start at } t \text { from } s_{j} \\
0, \text { otherwise }
\end{array}\right.
$$

\section{Objective Function}

Suppose the time sequence resources are occupied by the historical order input too early. In that case, the remaining complete time sequence for the whole audience is too few, which will affect the sales of the carrier resources in the advertising system. Therefore, after the order arrangement input is arranged, the order arrangement input of the audience group with no conflict or inaccurate audience is arranged for the same period. It will save time axis resources as shown in Fig. 4, when Input2 does not need to refine the audience group, the blank time axis resources of the whole audience. Therefore, the larger the frequency of different orders sharing, the better.

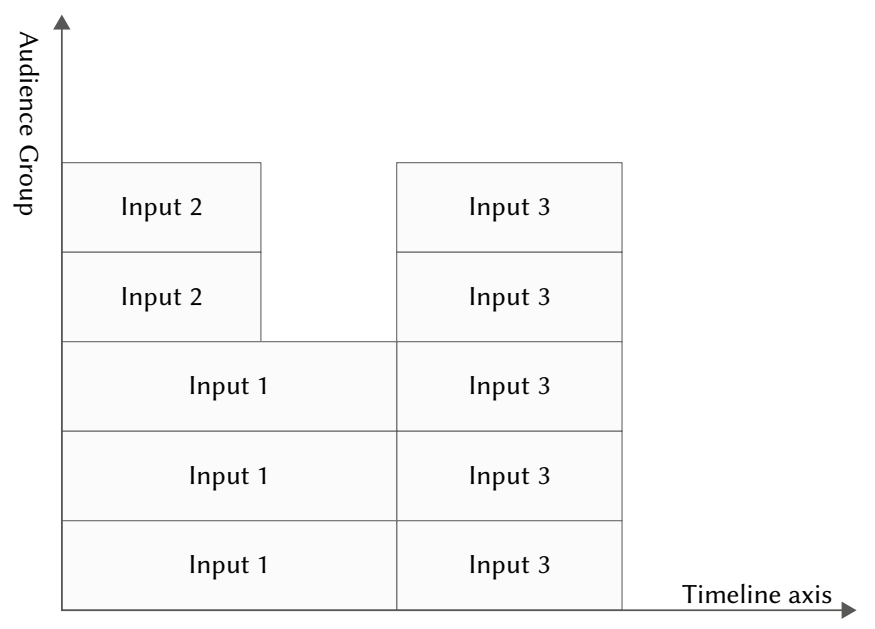

Fig. 4. Time axis and audience resource planning.

The objective is expressed by a mathematical formula as follows:

$$
\max \sum_{t=0}^{T}\left[\sum_{r=t}^{t+l_{i}} X_{i j}(r)\right]^{2}
$$

The arrangement results should satisfy the number of audience and group selection in the order. When the number of audiences is specified in the order, the system needs to arrange specific audience groups for it [13]. In most cases, the audience group set's total audience cannot be precisely equal to the older audience's number of days. It is necessary to reduce the deviation ratio of the number of audiences as far as possible. It is because if the number of arranged audiences is less than the number of orders required, then the revenue of billing and settlement based on the actual delivery results will be lost; if the number of arranged audiences exceeds the standard, then the more released audience resources do not belong to the billing and settlement scope of the order. There is no benefit to the system. It is undoubtedly a waste of audience resources. The objective is expressed by a mathematical formula as follows [14]:

$$
\min \frac{\mid \sum_{j=1}^{G} X_{i j}(t) \cdot s_{j}-\text { Total }_{i} \mid}{\text { Total }_{i}} \times 100 \%
$$

When the order scheduling input has the requirement of precise time delivery, if the scheduling result does not meet the requirement, it will cause a penalty in advance or delay. Therefore, the penalty amount should be minimized

$$
\sum_{i=0}^{N} \sum_{j=0}^{G} \alpha P_{i} \bullet\left[\sum_{t=0}^{d_{i}-1}\left(d_{i}-t\right) \bullet X_{i j}(t)+\sum_{t=d_{i}+1}^{T}\left(t-d_{i}\right) \cdot X_{i j}(t)\right]
$$

Any two different order scheduling inputs $I_{i^{\prime}} I_{k^{\prime}}, \forall i \neq k, i, k \in[1, N]$ cannot occupy the same user group in the same period. Otherwise, it will cause a resource conflict, which belongs to the category of infeasible solution. The mathematical expression of the constraint is expressed as follows:

$$
X_{i j}(r)=0, \forall r \in\left[t, t+l_{k}\right], \text { if } X_{k j}(t)=1
$$

As the basis of the order price, the certainty required in the arrangement and input of order type demand must be met or guaranteed as far as possible. The results of the agreement should meet the requirements of the number of audiences for each order arrangement input

$$
\sum_{j=1}^{G} X_{i j}(t) \bullet s_{j} \geq \text { Total }_{i}, \forall i \in[1, N]
$$

For the order arrangement input with accurate audience group requirements, the arrangement results should meet the needs of audience group selection, which is expressed by a mathematical formula as follows:

$$
\begin{aligned}
\vec{X}_{i}(t)= & \left(X_{i 1}(t), \ldots, X_{i j}(t), \ldots, X_{i G}(t)\right)=\vec{S}_{i} \\
& \text { if } \vec{S}_{i} \neq 0, \forall i \in[1, N]
\end{aligned}
$$

The resource planning model of the multi-objective optimization problem is constructed.

\section{A genetic Algorithm for Solving the Mathematical Model of TRIZ Theory-BAsed Advertisement}

\section{A. Solving Problems}

Generally speaking, there is no an optimal solution for multiobjective optimization problems. All possible solutions are called noninferior solutions, known as Pareto solutions [15]. To improve the performance of one sub-target, the understanding of the other subtargets may decrease. Therefore, multiple sub objectives cannot achieve optimal results at the same time. It can coordinate the compromise among the sub-objectives, and finally, get the better solution.

The solution to the classical combinatorial optimization problem mainly depends on constraints. As long as the conditions are sufficient, the optimal combination scheme can be uniquely determined. As the 


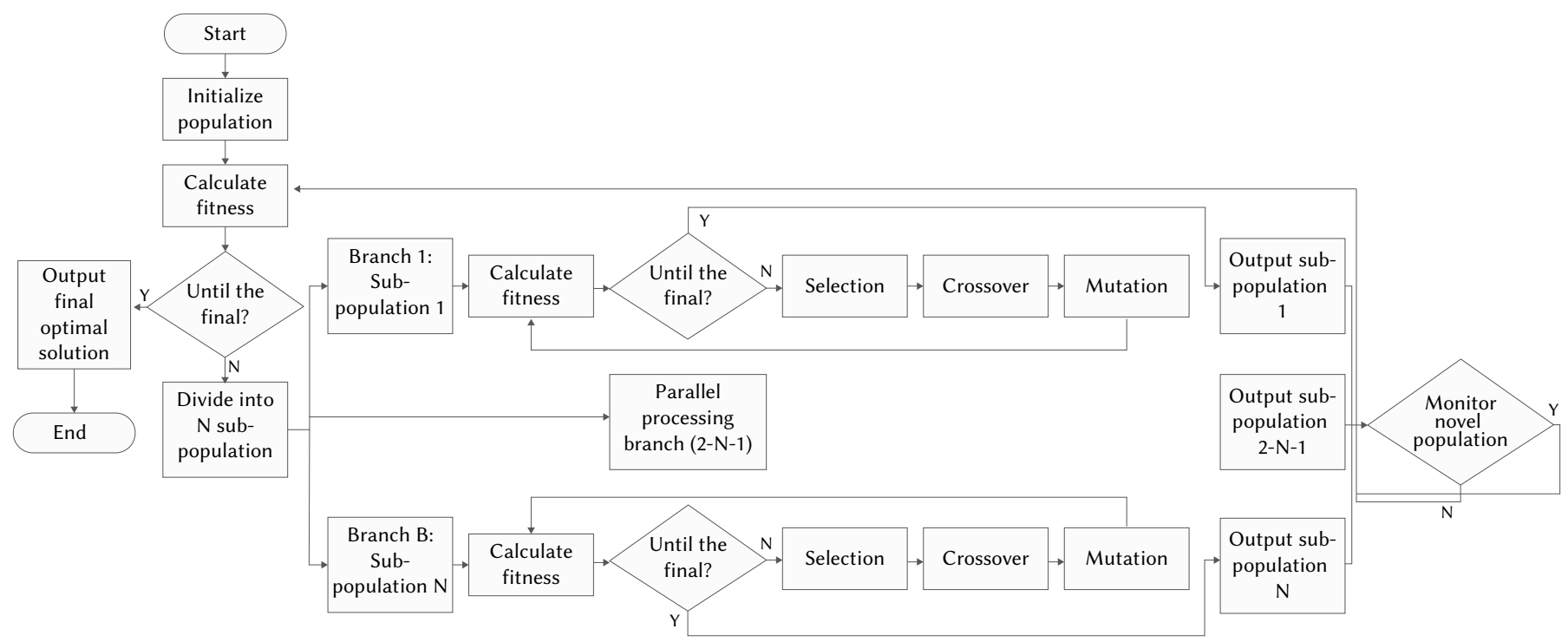

Fig. 5. Mathematical model of TRIZ theory based advertisement solved by the genetic algorithm.

number of composite objects increases rapidly, the solution becomes very complicated. It is called a "combined explosion." The classical programming method is usually feasible in theory for solving such problems. It is not suitable for practical issues. Therefore, how to take appropriate measures to suppress the "combination explosion" from the actual situation and to adopt the proper algorithm to reduce the search space has become a key problem in the arrangement and solution.

\section{B. Design of Parallel Genetic Algorithm}

A genetic algorithm (GA) [16] is an imitation of the mechanism of selection, crossover, and mutation in the process of biological genetics and evolution. For completing the search algorithm for the optimal solution of the problem, a genetic algorithm has the characteristics of parallel search, population optimization, and strong robustness. It has been widely used to solve nonlinear programming problems. At present, several commonly used multi-objective genetic algorithms are parallel selection method, non-inferior hierarchical genetic algorithm, a genetic algorithm based on objective weighting method, multi-objective particle swarm optimization algorithm. In this model, because the range of the objective function cannot be normalized, it is not suitable to use the accurate weighting method. Therefore, the parallel selection method with relatively simple selection steps is called "vector estimation multi-objective genetic algorithm [17]".

The core idea of genetic algorithms based on parallel selection to realize the content arrangement model is: using the gene coding value of chromosome to express the arrangement result; dividing the initial population into several subpopulations according to the number of targets; each population solves the whole space of genetic algorithm under a single objective function assigned by each population and the constraint conditions, and focuses on the local search with high performance. It is not easy to fall into the minimal local solution space, as to generate new subpopulations: merge all the new subpopulations, select cross mutation, recycle the previous processing to the termination condition, and then obtain the Pareto optimal solution of the problem. The flow chart is shown in Fig. 5.

\section{The Solving Process of the Parallel Genetic Algorithm}

\section{Chromosome Coding}

In this paper, the binary coding strategy is used to map the problem's solution space to a binary string space $\{0,1\}$. The selection principle of bit string length is based on the problem's precision and range of solution. The value of the bit string should cover all values of uniform discretization in the variable definition domain. Considering the definition of model variables, three types of gene atoms should be declared: the starting time point of order content, the end time point of order content, and the audience group. Three gene atoms were concatenated to form a gene representing the arrangement result. Then, $N$ genes were sequentially connected according to the number sequence of $\mathrm{N}$ orders, forming chromosomes.

Suppose three orders for the problem to be solved in this paper, with 5 audience groups. Then, the number of digits of chromosome can be defined as 45 , the number 1-5 represents the starting time point of order No.1, bits 6-10 represent the end time of order No.1, and bits 11-15 describe the selection of order No.1 to five audience groups (multiple groups can be selected). The second to fifth-order genes were organized according to the first gene structure and then continued successively, forming 45 chromosomes. In this way, the solution space is mapped to the gene space of chromosome. As long as the chromosome is decoded according to the inverse process of tissue structure, the solution can be obtained.

\section{Initial Population Selection}

The initial population has diversity. It can be obtained by the random method and selective experience method. Considering that some orders have specific requirements to meet, such as selecting audience groups, precise time delivery, etc., this paper uses the selection experience method to generate the initial population meeting these deterministic requirements. Therefore, the constraint condition (F) and objective function $(\mathrm{C})$ of the model degenerate and disappear (except when the gene mutation operation occurs), the solution space is converged in the initial population selection. The generated population is closer to the optimal solution space than the random population, improving the solution speed. Because of the parallel selection genetic algorithm, the initial population size is divided into three populations.

\section{Fitness Function}

Individual fitness is the basis of a genetic algorithm for the survival of the fittest. The most commonly used fitness evaluation method, namely "original fitness function, " directly uses the problem's objective function as the fitness function. The three constraints in the model are constructed into penalty functions, which need to be attached to three objective functions. As the fitness function of the three populations, $F_{1}, F_{2}, F_{3}$. 


\section{Selection, Crossover, and Variation}

Selection is a survival process of the fittest, and those with high fitness can be inherited and copied to the next generation with high probability [18]. There are many selection operators, such as elite individual retention strategy, tournament selection method, etc. Because of the complexity of the layout model, this paper chooses the roulette method. The selection probability of individuals is as follows:

$$
P_{i}=\frac{f_{i}}{\sum_{j=1}^{N} f_{j}}
$$

Among them $N$ is the population size and $f_{j}$ is the fitness value of the $j-t h$ individual in the population. The realization process is as follows: random number $r$ is generated in the interval $[0,1]$ if the conditions are satisfied:

$$
\sum_{j=0}^{i-1} P_{j} \leq r \leq \sum_{j=0}^{i} P_{j}
$$

Then the $i-t h$ individuals were selected, where $P_{0}=0$.

Crossover [19] is when some genes of two parents replace each other to produce new individuals. In this paper, Authors use the uniform crossover method: randomly generate binary bit string of chromosome length as the crossover template, where 0 means no exchange, 1 means exchange; according to the template, Authors can get new individuals. Generally, the crossover probability is [0.4, 0.99], and the crossover probability used in this paper is 0.6.

Mutation [20] is to change the algorithm's local search ability and maintain the population's diversity to change some genes of individuals on a binary coded chromosome. The mutation is reversing the gene value of some genes, that is, 1 to 0,0 to 1 . The method of uniform variation is used in this paper. The mutation probability was set as 0.05 . Generally, the evolutionary algebra is $100-1000$ times. Due to the parallel selection genetic algorithm, each population adopts 200 times of evolutionary algebra.

\section{Simulation Experiment and Result AnAlysis}

\section{A. Simulation Results}

In the general microcomputer environment, Python software's parallel genetic algorithm is implemented [21]. Suppose the current mobile advertising business. The carrier resources are composed of 1 spatial location, five audience groups [1,5], and 10-time units [1,10]. Due to media resources limitation, it is necessary to plan orders in these timelines and audience resources. The number of audience groups is set, as shown in Table II.

TABLE II.the Number of People in the Audience Group

\begin{tabular}{lcccc}
\hline Audience group $j$ & 1 & 2 & 3 & 4 \\
Number of humans $S_{j}$ & 180 & 120 & 230 & 280 \\
\hline
\end{tabular}

The number of input data of order arrangement increases by 5 at a time. The values are $\{5,10,15, \ldots, 45,50\}$. The input data is shown in Table III. Assuming the penalty coefficient $\alpha=0.3$, the parallel genetic algorithm proposed in this paper is used to solve the problem.

TABLE III. Input Data of PArtial Order Arrangement

\begin{tabular}{cccccc}
\hline $\begin{array}{c}\text { Order } \\
\text { input } \boldsymbol{I}_{\boldsymbol{i}}\end{array}$ & Price $\boldsymbol{P}_{\boldsymbol{i}}$ & $\begin{array}{c}\text { Audience } \\
\text { Group } \vec{S}_{\boldsymbol{i}}\end{array}$ & $\begin{array}{c}\text { Audience } \\
\text { Number Total }\end{array}$ & $\begin{array}{c}\text { Sequence } \\
\text { start } \boldsymbol{d}_{\boldsymbol{i}}\end{array}$ & $\begin{array}{c}\text { Time } \\
\text { length } \boldsymbol{I}_{\boldsymbol{i}}\end{array}$ \\
\hline $\mathbf{1}$ & 290 & $\{1,1,1,0,0\}$ & 480 & 0 & 2 \\
$\mathbf{2}$ & 240 & - & 420 & - & 1 \\
$\mathbf{3}$ & 480 & $\{1,1,1,1,1\}$ & 780 & - & 3 \\
\hline
\end{tabular}

Solve the model variables based on $X_{i j}(t)$, and transform them into natural language description results, as shown in Fig. 5. Table IV shows part of the operation results, and the simulation results show a better solution based on the model objectives and constraints. It is verified that the model can solve the problem of content arrangement.

Table IV. Partial Results of a Parallel Genetic Algorithm Based on TRIZ THEORY

\begin{tabular}{cccccc}
\hline $\begin{array}{c}\text { Order } \\
\text { input } \boldsymbol{I}_{\boldsymbol{i}}\end{array}$ & $\begin{array}{c}\text { Audience } \\
\text { Group } \vec{S}_{\boldsymbol{i}}\end{array}$ & $\begin{array}{c}\text { Audience } \\
\text { Number } \text { Total }_{\boldsymbol{i}}\end{array}$ & $\begin{array}{c}\text { Sequence } \\
\text { start } \boldsymbol{d}_{\boldsymbol{i}}\end{array}$ & $\begin{array}{c}\text { Time } \\
\text { length } \boldsymbol{I}_{\boldsymbol{i}}\end{array}$ & $\begin{array}{c}\text { Order } \\
\text { input } \boldsymbol{I}_{\boldsymbol{i}}\end{array}$ \\
\hline $\mathbf{1}$ & $\{1,1,1,0,0\}$ & 476 & 0 & 2 & 1 \\
$\mathbf{2}$ & $\{0,0,0,1,1\}$ & 418 & 0 & 1 & 2 \\
$\mathbf{3}$ & $\{1,1,1,1,1\}$ & 778 & 2 & 3 & 3 \\
\hline
\end{tabular}

\section{B. Analysis of Experimental Results}

In this paper, the weighted average method is used to set each objective's weight coefficient based on the importance of each objective, and the multi-objective is transformed into a single objective. The classical dynamic programming method is used to solve the problem. The simulation efficiency is shown in Fig. 6. With the increase of the problem's scale, the number of iterations and the running time of the dynamic programming method [22] increase exponentially; that is, there is a combinatorial explosion problem. In contrast, the parallel genetic algorithm's time performance is relatively stable, and the average convergence time is shorter than that of the dynamic programming method. When the order size is more than 30 , the parallel genetic algorithm is suitable for solving the problem.

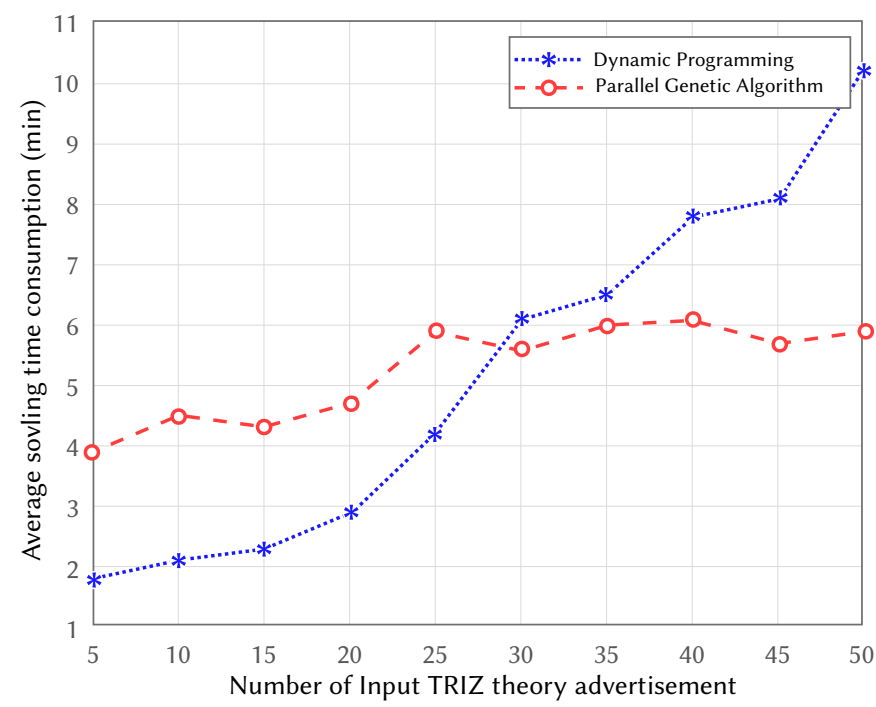

Fig. 6. Comparison results of dynamic programming algorithm and parallel genetic algorithm.

When there are a few orders, a relatively simple dynamic programming method can be used. Therefore, the parallel genetic algorithm has a high application value in engineering with more demands, complex scheduling requirements, and non-real-time request-response. When the problem's scale is enlarged and the time precision is improved, the chromosome's binary code string will overgrow. The real coded genetic algorithm can be used to design chromosomes and algorithms, reducing a genetic algorithm's search space. The increasing algorithm's evolutionary algebra method is used to increase the number of individuals in the solution space to improve the Pareto optimal solution's probability. Designers work for smaller develop outsourcing companies or others who work freelance work on 
the job, or the contract basis adapts their working day to the customers' schedules and deadlines. Freelance designers have to satisfy customers and look for new ones to sustain their stable incomes. In this setting, graphic designers do freelance work full-time or part-time in addition to a paying job in the design or other workplace. In advertising, the graphic designers use details such as a customer's desires, planned design messages, and appeal before producing a new design for consumers or users. Graphic designers collect and conduct their research on their projects through interactions with buyers, creative or art directors. When graphical designers acquire this knowledge, they create designs or layouts to output their design visions by hand or using a computer and include colors, music, artwork, photography, animation, design styles, and other visual objects. Graphic designers then choose an element to view on a website or screen, create graphs and diagrams of data to be released and consult copywriters on text accompanying the design. Clients or art/creative directors are then presented with completed designs.

\section{Conclusion}

This paper verifies the feasibility of the combination of TRIZ theory and creative thinking through logical analysis, analyzes the process of stimulating divergent thinking, aggregation thinking, and transformation of innovative thinking methods from the innovation principle of TRIZ theory as the origin, and applies it to the creative mechanism and application program of print advertising creativity. The specific principles and rational principles can stimulate perceptual thinking and abstract imagination, seek breakthroughs based on original creative thinking methods, explore the source of thinking, and provide a more feasible and practical creative thinking method of print advertising. It gives the application basis for the development of TRIZ theory in many fields and provides detailed theoretical guidance for the construction of print advertising's creative thinking method. Based on the TRIZ innovation theory, computer print advertisement design needs to complete the arrangement of content. In this paper, the media resources of content media arrangement are constructed into a three-dimensional resource model that takes the carrier as the core and describes the template screen space, time sequence resources, audience grouping, and other three-dimensional resources model. A multi-objective resource optimization mathematical model content arrangement is constructed based on the order demand constraints, high resource utilization, and accurate delivery time goal. Finally, a multi-objective optimization mathematical model of a parallel genetic algorithm is designed to solve the advertisement content arrangement. Experiments verify the innovative thinking of TRIZ and the application of genetic algorithm in content arrangement of computer graphic advertisement design.

\section{REFERENCES}

[1] C. H. Lee, C. H. Chen, F. Li, A. J. Shie, "Customized and knowledgecentric service design model integrating case-based reasoning and TRIZ," Expert Systems with Applications, vol.143, pp.113062, 2020, https://doi. org/10.1016/j.eswa.2019.113062.

[2] F. Li. "A Study on Innovative Design of Rotary Pile Foundation Drilling Machine Based on TRIZ Theory," In International Conference on Mechanical Design, Springer, Singapore, 2019, pp. 302-309.

[3] N. Şen, Y. Baykal. "Development of car wishbone using sheet metal tearing process via the theory of inventive problem-solving (TRIZ) method", Journal of the Brazilian Society of Mechanical Sciences and Engineering, vol.41, no.10, pp.390,2019, https://doi.org/10.1007/s40430019-1884-7.

[4] F. Jiang, J. Shen, T. Zhu, J. Wen. "Design of Flagstone Transport Device Based on TRIZ Theory", In International Conference on Mechanical Design, Springer, Singapore, 2019, pp. 253-266.
[5] D. Russo, C. Spreafico, M. Spreafico. "A Simplified TRIZ Approach Involving Technology Transfer for Reducing Product Energy Consumption", In Sustainable Design and Manufacturing, Springer, Singapore, 2020, pp. 129-138.

[6] H. D. García-Manilla, J. Delgado-Maciel, D. Tlapa-Mendoza, Y. A. BáezLópez, L. Riverda-Cadavid. "Integration of design thinking and TRIZ Theory to assist a user in the formulation of an innovation project", In Managing innovation in highly restrictive environments, Springer, Cham, 2019, pp. 303-327.

[7] K. Hmina, M. Sallaou, A. Arbaoui, L. Lasri. "A preliminary design innovation aid methodology based on energy analysis and TRIZ tools exploitation", International fournal on Interactive Design and Manufacturing, vol.12, no. 3, pp. 919-928, 2018, https://doi.org/10.1007/ s12008-017-0455-3

[8] G. Bersano, P. E. Fayemi. "Application of TRIZ and Innovation Management Theory on Decision Support for Transport Infrastructure", In International TRIZ Future Conference, Springer, Cham, 2019, pp. 486-493.

[9] P. Livotov, A. P. C. Sekaran, R. Law, Reay. D. "Systematic Innovation in Process Engineering: Linking TRIZ and Process Intensification", In Advances in Systematic Creativity, Palgrave Macmillan, Cham, 2019, pp. 27-44.

[10] S. Purnamawati, E. B. Nababan, B. Tsani, R. Taqyuddin, R. F. Rahmat. "Advertisement scheduling on commercial radio station using genetics algorithm", 2nd International Conference on Computing and Applied Informatics, Medan, Indonesia, 2017, pp. 28-30.

[11] Q. Madera, O. Castillo, M. Garcia, A. Mancilla. "Interactive evolutionary computation with adaptive mutation for increasing the effectiveness of advertisement texts", In 2016 IEEE Symposium Series on Computational Intelligence, IEEE, 2016, pp. 1-6.

[12] G. T. Reddy, M. P. K. Reddy, K. Lakshmanna, D. S. Rajput, R. Kaluri, G. Srivastava. "Hybrid genetic algorithm and a fuzzy logic classifier for heart disease diagnosis", Evolutionary Intelligence, vol. 13, no. 2, pp. 185196, 2020, https://doi.org/10.1007/s12065-019-00327-1.

[13] L. Qin, W. Huang, Y. Du, L. Zheng, M. K. Jawed. "Genetic algorithm-based inverse design of elastic gridshells", Structural and Multidisciplinary Optimization, vol.62, pp. 2691-2707, 2020, https://doi.org/10.1007/s00158020-02639-8.

[14] M. Guo. "A Study on Data Mining of Digital Display Performance of Brand Advertisement", Wireless Personal Communications, vol. 102, no. 2, pp. 1243-1253, 2018, https://doi.org/10.1007/s11277-017-5180-5.

[15] K. M. Hamdia, X. Zhuang, T. Rabczuk. "An efficient optimization approach for designing machine learning models based on genetic algorithm", Neural Computing and Applications, vol.33, pp. 923-1933, 2021, https://doi.org/10.1007/s00521-020-05035-x.

[16] Z. Zhou, F. Li, H. Zhu, H. Xie, J. H. Abawajy, M. U. Chowdhury. "An improved genetic algorithm using greedy strategy toward task scheduling optimization in cloud environments", Neural Computing and Applications, vol. 32, no. 6, pp. 1531-1541, 2020, https://doi.org/10.1007/ s00521-019-04119-7.

[17] H. Chung, K. S. Shin. "Genetic algorithm-optimized multi-channel convolutional neural network for stock market prediction", Neural Computing and Applications, vol. 32, no.12, pp. 7897-7914, 2020, https:// doi.org/10.1007/s00521-019-04236-3.

[18] J. Tian, M. Gao, G. Ge. "Wireless sensor network node optimal coverage based on improved genetic algorithm and binary ant colony algorithm", EURASIP Journal on Wireless Communications and Networking, 2016:104, 2016, doi: 10.1186/s13638-016-0605-5.

[19] T. L. Chen, C. Y. Cheng, Y. H. Chou. "Multi-objective genetic algorithm for energy-efficient hybrid flow shop scheduling with lot streaming", Annals of Operations Research, vol. 290, pp. 813-836, 2020, https://doi. org/10.1007/s10479-018-2969-x.

[20] N. Malarvizhi, P. Selvarani, P. Raj. "Adaptive fuzzy genetic algorithm for multi biometric authentication", Multimedia Tools and Applications, Vol.79. no.13, pp. 9131-9144, 2020, https://doi.org/10.1007/s11042-0197436-4.

[21] C. Ma, W. Hao, F. Pan, W. Xiang. "Road screening and distribution route multi-objective robust optimization for hazardous materials based on neural network and genetic algorithm", PLoS One, vol. 13, no. 6, pp. e0198931, 2018, https://doi.org/10.1371/journal.pone.0198931.

[22] A. Mondal, J. M. Young, T. A. Barckholtz, G. Kiss, L. Koziol, A. Z. 
Panagiotopoulos. "Genetic algorithm driven force field parameterization for molten alkali-metal carbonate and hydroxide salts", fournal of Chemical Theory and Computation, vol. 16.no. 9, pp.5736-5746, 2020, http://dx.doi.org/10.1021/acs.jctc.0c00285.

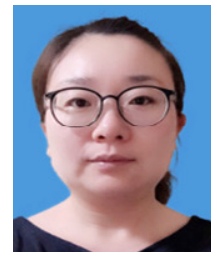

\section{Yang Song}

Yang Song, graduated from the Beijing Institute of Graphic Communication of Design art in 2008. Working in School of Academy of fine arts, Baotou Teachers College. Her research interests include Digital media art Design. 